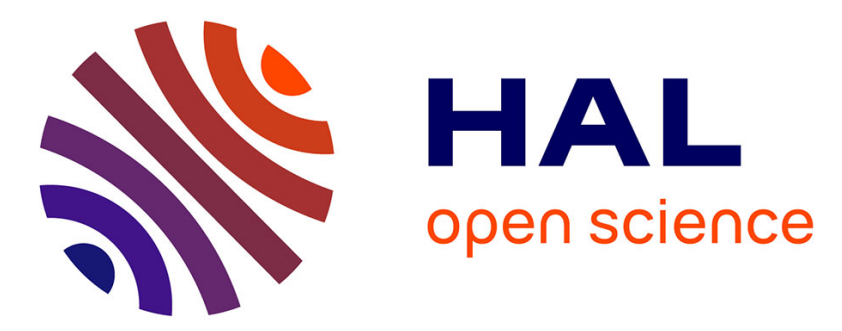

\title{
Abradable coating removal in turbomachines: a macroscopic approach accounting for various wear mechanisms
}

Bérenger Berthoul, Alain Batailly, Mathias Legrand, Laurent Stainier, Patrice Cartraud

\section{To cite this version:}

Bérenger Berthoul, Alain Batailly, Mathias Legrand, Laurent Stainier, Patrice Cartraud. Abradable coating removal in turbomachines: a macroscopic approach accounting for various wear mechanisms. ASME Turbo Expo 2015: Turbine Technical Conference and Exposition, ASME, Jun 2015, Montréal, Canada. 10.1115/GT2015-42500 . hal-01188846

\section{HAL Id: hal-01188846 https://hal.science/hal-01188846}

Submitted on 19 Mar 2016

HAL is a multi-disciplinary open access archive for the deposit and dissemination of scientific research documents, whether they are published or not. The documents may come from teaching and research institutions in France or abroad, or from public or private research centers.
L'archive ouverte pluridisciplinaire HAL, est destinée au dépôt et à la diffusion de documents scientifiques de niveau recherche, publiés ou non, émanant des établissements d'enseignement et de recherche français ou étrangers, des laboratoires publics ou privés.

\section{다(1)(2)}

Distributed under a Creative Commons Attribution - ShareAlikel 4.0 International 


\title{
Abradable coating removal in turbomachines: a macroscopic approach for various wear mechanisms
}

\author{
Bérenger Berthoul ${ }^{1}$, Alain Batailly ${ }^{2}$, Mathias Legrand ${ }^{2}$, Laurent Stainier ${ }^{1}$, and Patrice Cartraud ${ }^{1}$
}

\begin{abstract}
Abradable materials are widely used as a coating within compressor and turbine stages of modern aircraft engines in order to reduce operating blade-tip/casing clearances and thus maximize the engine energy efficiency. However, recent investigations revealed that the interaction between a blade and these materials may threaten blades structural integrity. Consequently, there is a need for a better understanding of the physical phenomena at play and for an accurate modeling of the interaction in order to predict hazardous events. The cornerstone of related numerical investigations lies in the modeling of the abradable coating removal due to the blade/abradable coating interaction and the associated contact forces along the contact interface. In this context, this article presents a macroscopic model for abradable coating removal accounting for key wear mechanisms including adhesive wear, abrasive wear, micro-rupture wear and machining wear. It is coupled with an in-house numerical strategy for the modeling of full 3D blade/abradable coating interactions within turbomachines and applied to an aircraft engine. Numerical results are compared with respect to existing models and available experimental data. The applicability of the proposed model for 3D interaction simulations is underlined as well as the consistency of the obtained results with experimental observations.
\end{abstract}

\section{Keywords}

Abradable coatings, turbomachines, wear

${ }^{1}$ Institut de recherche en Génie Civil et Mécanique, Ecole Centrale de Nantes, 1 rue de la Noë, BP 92101, 44321 Nantes, France ${ }^{2}$ McGill University, McDonald engineering building, 817 Sherbrooke West, Montréal H3A 0C3, Canada

\section{Introduction}

Abradable coatings have long been used by aircraft engines manufacturers as a sacrificial material in order to reduce operating clearances in both compressor and turbine stages. These coatings advantageously mitigate potential parasitic leakage flows from a stage to the previous one and are easily worn off in case contacts occur with one of the blades thus preventing potentially hazardous structural damages. The nature of the material coating and its mechanical properties are adjusted depending on where it is applied in the engine: as an example, a coating sprayed on the casing of a low-pressure compressor does not require the same thermal resistance as one sprayed in the high-pressure turbine. Accordingly, there is a wide range of materials used as abradable coatings such as ceramics, aluminum/silicon alloys and nickel/graphite composites to name a few. These materials may be sprayed, sintered or even deposited with a honeycomb structure on the casing. Consequently, when blade-tip/abradable coating contacts occur, a large variety of mechanisms may be at play. It has been recently shown that if a blade/abradable contact does not threaten the blade integrity by itself, repeated contacts could lead to a resonance of the blade [1].

The experimental setup described in [1] involves the last stage of a full-scale aircraft engine low-pressure compressor operating under vacuum. Contact between the blade and the abradable coating is initiated through centrifugal effects. The interaction happens for only one blade, designed to be slightly longer. The blade tip shows high amplitude response, and the coating is worn out at six equally spaced locations along the casing circumference, called wear lobes.

Numerical simulations have already been carried out in [2] where the abradable is represented by a one-dimensional elastovisco-plastic material. This model allows for the prediction of the blade structural response of experiment [1]. Nevertheless, it is mostly numerical, since the coating wear is taken into account by a permanent deformation of the abradable instead of a material loss.

A key element for the quantitative study of the movement of the blade is an accurate modeling of the interaction behavior. This paper presents a simplified macro-scale model of the interaction, based on the phenomenology and physics of abradable wear.

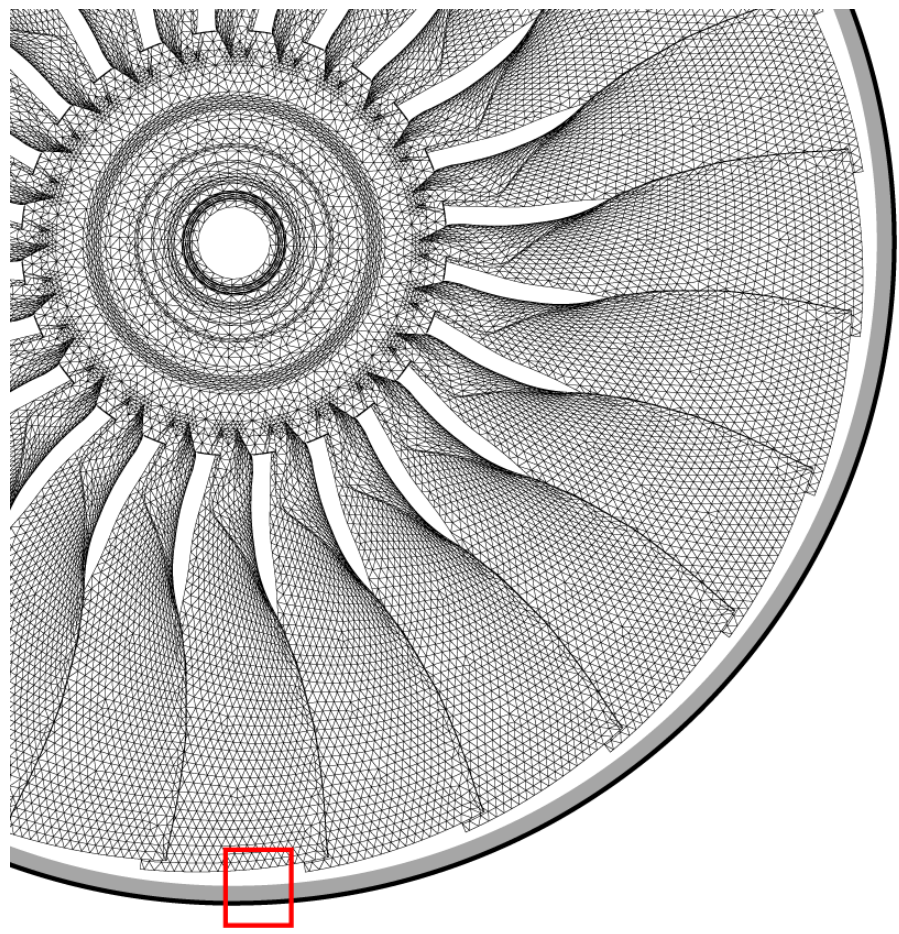

Figure 1. Partial view of the fan stage of an aircraft engine. A zoom over the red square is depicted in Fig. 2

The goal of this model is to depend only upon experimentally measurable material quantities. It has been implemented in the framework presented in [2].

The first section is a brief review of the phenomenology of abradable wear and its synthesis according to the underlying physical mechanisms. Then an attempt is made to model these mechanisms under simplifying assumptions. Finally, the numerical framework is briefly discussed before results are presented through two case studies.

Note on scales In the following, the macro scale refers to the scale of the blade $(\sim 10 \mathrm{~mm})$, the micro scale is the scale of the abradable rugosity, where the surface of the abradable can no longer be considered smooth with a well-defined normal $(\sim 1 \mu \mathrm{m})$ and the meso scale is very small compared to the blade, 


\begin{tabular}{|c|c|c|c|}
\hline \multicolumn{2}{|c|}{ Nomenclature } & $F_{n}$ & Normal force exerted onto the blade \\
\hline & & $F_{t}$ & Tangential force exerted onto the blade \\
\hline$\Delta h^{\mathrm{X}}$ & Worn thickness of the abradable due to wear mechanism X & $I$ & Incursion of the blade in the coating \\
\hline$\mu$ & Coulomb friction coefficient & $k^{\mathrm{ab}}$ & Archard's law coefficient for abrasive wear \\
\hline$\sigma_{n}$ & Stress component normal to the abradable surface & $k^{\mathrm{ad}}$ & Archard's law coefficient for adhesive wear \\
\hline $\begin{array}{l}\sigma_{y} \\
\tau_{y}\end{array}$ & Elasticity limit (shear) & $l_{\mathrm{pa}}$ & Average length of particles detached by micro-rupture \\
\hline $\begin{array}{l}E_{\mathrm{a}} \\
e_{\mathrm{a}}\end{array}$ & $\begin{array}{l}\text { Young's modulus of the abradable } \\
\text { Thickness of the abradable }\end{array}$ & $n_{\mathrm{pa}}$ & $\begin{array}{l}\text { Number of abradable material particles per unit length bound } \\
\text { to the blade and thus abrading the coating }\end{array}$ \\
\hline$e_{\mathrm{b}}$ & Thickness of the blade & $p$ & Hardness \\
\hline
\end{tabular}

but where the normal to the coating is defined $(\sim 100 \mu \mathrm{m})$.

\section{Phenomenology of abradable wear}

The large number of recent publications dealing with abradable coatings shows the need for a better understanding of the structural behavior of such materials when impacted by a rotating blade. From an experimental standpoint, several studies may be found regarding the static characterization of abradable coatings [3, 4]. Similarly, several abradability investigations carried out statically — or at very low speed — are available [5] in addition to a few scratch tests [6]. In the context of turbomachinery, one should mention the pioneering work [7] on wear mechanisms in gas turbines as well as the work of Schmid [8] which will be our main source of information regarding the phenomenology of abradable materials. Recently, experimental investigations on the dynamic characterization of abradable coatings within a simulated turbomachine environment were reported with respect to: a high relative interaction speed [9] (from 100 to $500 \mathrm{~m} / \mathrm{s}$ ), elevated temperatures [10] (up to $600^{\circ} \mathrm{C}$ ) as well as a combination of high interaction speed and elevated temperatures [11, 12]. While the influence of thermal conditions has long been investigated [13], experimental work carried out by industrials is rarely published.

To the authors' knowledge, there is no quantitative model of abradable wear in the literature. A few qualitative models of abradable wear based on experimental observations were proposed by Schmid [8]. A finite element micro model of the bulk material only is proposed in [14]. Finally, two abradable coating models in the context of full 3D simulations have been described [LEGRAND2011, 15], but they have been developed focusing on numerical efficiency rather than physical rendering of wear phenomena.

\subsection{Methodology}

For a given abradable coating, wear and removal involve several complex mechanisms. In the following, the focus is made on three of these mechanisms, assumed dominant during the interaction with a rotating blade [8]: (1) cutting, (2) permanent deformation, and (3) micro-rupture. Further refinement of the model including other wear mechanisms such as transfer and fusion goes beyond the scope of this study. Based on the proportion of removal with respect to the coating thickness, see Fig. 2, the bulk behavior of the abradable material is assumed elastic.

For each phenomenon of interest, the modeling approach may be summed up as follows:

- a brief description is provided based on existing publications,

- the underlying physics is detailed focusing on the forces the abradable coating is subjected to,

- a relation between the relevant quantities is given in order to quantify the phenomenon.

Also, the implementation of the proposed wear model within an existing numerical strategy for the simulation of blade/casing interactions implies that:

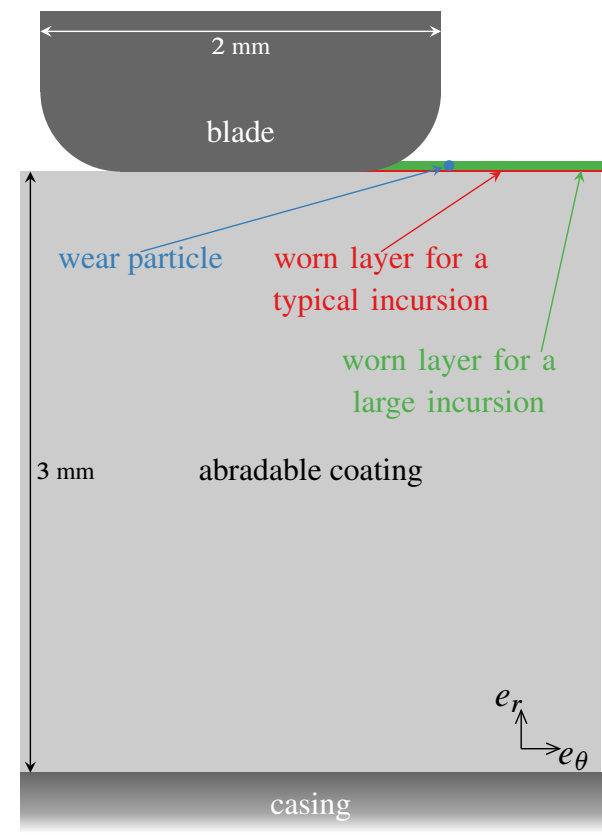

Figure 2. Schematic representation of coating removal. Proportions are respected.

- the macroscopic effect of wear is key. Thus computational power should not be dedicated to the solution of sophisticated PDEs to know the exact strain field within the abradable material,

- in this article, the proposed wear model is essentially macroscopic. This is justified by the fact that during a blade/casing interaction, the blade amplitudes of vibration do not seem to depend on micro scale quantities [1] (such as the precise topology of the surface of the abradable at the scale of the rugosity), but mostly depend on their macroscopic averages (the topology at the scale of the blade edge).

Table 1. Inputs and outputs of the model

\begin{tabular}{ll}
\hline inputs & $\begin{array}{l}\text { penetration of the blade into the abradable } \\
\text { blade edge velocity }\end{array}$ \\
\hline outputs & $\begin{array}{l}\text { contact forces exerted onto the blade } \\
\text { updated abradable surface geometry }\end{array}$ \\
\hline
\end{tabular}

The quantities of interest are described in Tab. 1. From now on, as a first step to model the interaction, we simplify the problem by neglecting thermal effects and blade wear. They are not coupled within the time-stepping scheme. However thermal effects can be taken into account by using parameters measured in an experiment where the temperature in the contact region is representative of a real interaction.

Note Formulas of the following paragraphs are given in the plane orthogonal to the axis of rotation, and some quantities such 
as forces are hence given by unit length. The term normal refers to vectors in the direction of $e_{r}$, and tangential refers to vectors in the direction of $e_{\theta}$ (cf. Fig. 2).

\section{Cutting}

Kinematics Existing experimental observations [7] suggest that the interpretation of the cutting mechanism may be arduous: it is reported that after the interaction, the material still attached to the coating is left with no deformation nor damage. However, the material was not removed by brittle rupture because it has a shiny appearance [7]. The abradable coating is cleanly cut by the blade, yielding a very smooth surface with no observable permanent deformation.

Forces Cutting may be explained by an adiabatic shear band mechanism [16]: due to the high velocity of the blade, deformation does not have time to propagate for elastic accommodation. Thus plastic deformations occur. The plastic work done is mainly dissipated as heat which does not have time to propagate (adiabatic). As a consequence, the material is soften on a narrow band where the material is easily sheared. So cutting is a kind of ductile rupture for high speed and/or high temperature. At the scale of the abradable material micro-structure, no deformation is observed, but it may be due to the fact that it should be localized at the extreme surface of the cut material. It should be noted that the development of shear bands in the abradable material can differ significantly according to the value of the blade incursion and two scenarii are considered:

- when the incursion depth is of the order of magnitude of the material rugosity, cutting is a form of adhesive wear [17] at high velocity/high temperature. In this configuration, friction and adhesive wear should be considered parts of the same mechanism, namely plasticity at junctions [17],

- for larger incursion depths [11], cutting should rather be assimilated to machining.

Formulations In the case of friction and adhesive wear, Coulomb friction and Archard's law will be used as they have proven to be a good approximation of the phenomena while using a reduced number of parameters:

$F_{t}^{\mathrm{fr}}=\mu F_{n}$

$\Delta h^{\mathrm{ad}}=\frac{k^{\mathrm{ad}} e_{\mathrm{b}} \sigma_{n}}{p}$

For the modeling of machining, the "deck of card" model [18]" is used, see Fig. 3. The force induced on the blade by machining is defined as:

$F_{t}^{\mathrm{ma}}=\tau_{y} \frac{\cos \phi}{\sin \phi} \Delta h^{\mathrm{ma}}$

For the wear of a clean cut, the formula reduces to:

$\Delta h^{\mathrm{ma}}=I-I_{\mathrm{e}}$

where $I_{\mathrm{e}}$, the elastic accommodation of the coating, is defined by

$I_{\mathrm{e}}=\frac{\sigma_{y} e_{\mathrm{a}}}{E_{\mathrm{a}}}$

The shear band angle, $\phi$ can depend on the blade geometry, temperature and interaction velocity.

${ }^{1}$ The continuous chip in experiments is visually similar to a "deck of card" morphology.

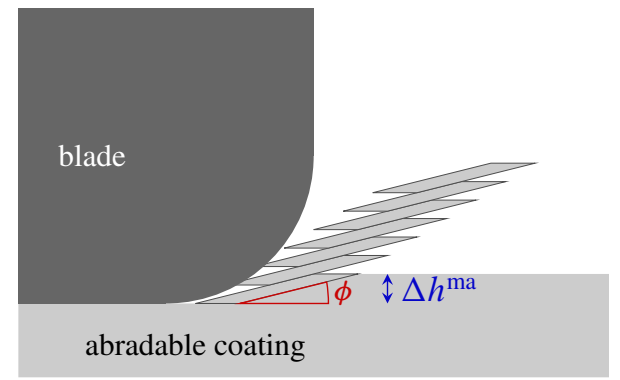

Figure 3. Deck of card model for machining. Material is removed by successive shear bands

\section{Permanent deformation}

Kinematics material is transferred to the blade and gives it a saw tooth profile. The abradable material is then ploughed by the blade.

Forces material transfer is linked to adhesive wear and is left for the sake of simplicity. Ploughing can be seen as abrasive wear in the terminology of Rabinowicz [17].

Formulation wear due to abrasion can be modeled by another Archard's law:

$\Delta h^{\mathrm{ab}}=k^{\mathrm{ab}} e_{\mathrm{b}} \frac{\sigma_{n}}{p}$

Regarding the force exerted on the blade, the following relation holds:

$F_{t}^{\mathrm{ab}}=F^{\mathrm{pp}} n_{\mathrm{pa}}$

where the number of particles along the blade edge $n_{p a}$ can be estimated by looking at the number of grooves on a post-mortem abradable specimen, and $F^{\mathrm{pp}}$, the ploughing force of one particle, can be estimated by scratch tests [6].

\section{Micro-rupture}

Kinematics packets of spray particles are pulled out of the surface by the blade, leaving a pock-marked abradable coating.

Forces the mechanism is associated to the rupture properties of the material. Abradable materials are quasi-brittle.

Formulation Assuming a simplified geometry, $c f$. Fig. 4, a statistical reasoning on energy dissipated when creating detached particles by brittle rupture gives:

$F_{t}^{\mathrm{mr}}=k^{\mathrm{mr}} \gamma$

where $k^{\mathrm{mr}}$ is a factor depending on the form of the particle and $\gamma$ is the surface energy of the abradable material. If the particle is a shell covering the coating before being detached, $k^{\mathrm{mr}}=2$. If it is a cube, then $k^{\mathrm{mr}}=6$. The worn thickness is then

$\Delta h^{\mathrm{mr}}=l_{\mathrm{pa}}$

\section{Summary}

A model has been proposed for each mechanism. They shall now be gathered to obtain the complete model.

First, it is assumed that friction/adhesive wear and abrasive wear are mutually independent and micro-rupture and machining happen for an elementary surface with respective proportions $p^{\mathrm{mr}}$ and $p^{\mathrm{ma}}$, with $0 \leq p^{\mathrm{mr}}+p^{\mathrm{ma}} \leq 1$, a zero proportion meaning that the mechanism is inactive. These proportions are dependent on interaction velocity, incursion and temperature. This allows for a representation of Schmid wear maps [8]. 


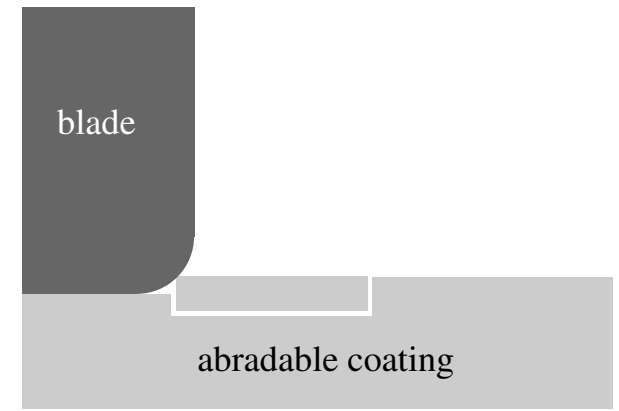

Figure 4. Micro-rupture wear. A particle is formed when the blade impacts the coating

One should also note that the kinematics of the detached material is of importance: Schmid [8] notes that for velocity interactions greater than $100 \mathrm{~m} / \mathrm{s}$, most of the detached material is released as particles at the rear of the blade. But in another experiment at high temperature $\left(300^{\circ} \mathrm{C}\right)$ and high incursions of the blade in the coating $(50 \mu \mathrm{m})$ [19], there is a continuous chip at the front of the blade, and in yet another experiment, also at high incursions but at room temperature, particles are released at the front of the machining tool [20]. Also, some mechanisms happen at the front of the blade (micro-rupture and machining) with particles being released either at the front or at the rear, while other happen under the blade (friction/adhesive wear and abrasive wear). So the scenario of interaction should be: (1) compute the forces due to micro-rupture and machining together and (2) update the topology of the abradable once, (3) compute the forces due to friction/adhesive wear and abrasive wear and (4) update the topology again. With simplified notation such as $\Delta h^{\mathrm{ad}}=\Delta h^{\mathrm{ad}}\left(\Delta h^{\mathrm{mr}}, \Delta h^{\mathrm{ma}}\right)$, the formula of abradable wear at the end of the interaction is thus:

$\Delta h=\Delta h^{\mathrm{ad}}+\Delta h^{\mathrm{ab}}+p^{\mathrm{mr}} \Delta h^{\mathrm{mr}}+p^{\mathrm{ma}} \Delta h^{\mathrm{ma}}$

Since all the mechanisms in this model are supposed to be caused by independent physical phenomena, the total energy given by the blade is the sum of the energies of each mechanisms (we neglect the kinetic energy of detached particles). This decomposition is also true for forces. Hence:

$F_{t}=F_{t}^{\mathrm{fr}}+F_{t}^{\mathrm{ab}}+p^{\mathrm{mr}} F_{t}^{\mathrm{mr}}+p^{\mathrm{ma}} F_{t}^{\mathrm{ma}}$

\section{Numerical framework}

Because our numerical framework has already been presented extensively in [21] and [2], only its main characteristics are described here: the blade geometry is meshed in 3D and its finite element matrices are obtained. They are then reduced with a Craig-Bampton component mode synthesis [22], in order to reduce the number of degrees of freedom while keeping unchanged the blade tip degrees of freedom for easy contact handling. Centrifugal hardening is taken into account. Then the blade/coating interaction problem is simulated with an explicit time integration scheme. The abradable coating is meshed with 1D abradable elements. At each time step, the contact is handled with a predictioncorrection procedure: a blade displacement is predicted and the facing abradable element is searched. When a penetration is detected, the force exerted by the abradable on the blade (computed based on the formulas of the preceding section) is used for the correction of the blade displacement. The wear of the abradable element is also computed for updating the coating topology.

At $t=0$, the blade is separated from the abradable coating by a positive clearance. The casing is considered to be rigid. It is perfectly circular at the beginning, and then progressively ovalized, such that at some point of the simulation, the blade comes into contact with the coating and begins to wear it.

\section{Results}

Note In the following, amplitudes are normalized with respect to reference data for confidentiality purposes.

\subsection{Comparison with the existing model}

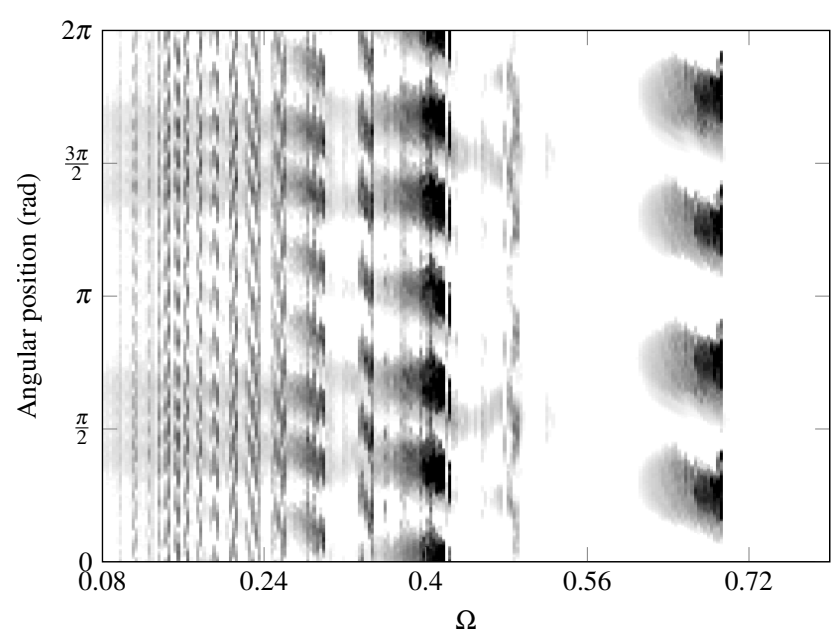

(a) Wear map for the reference law [21]

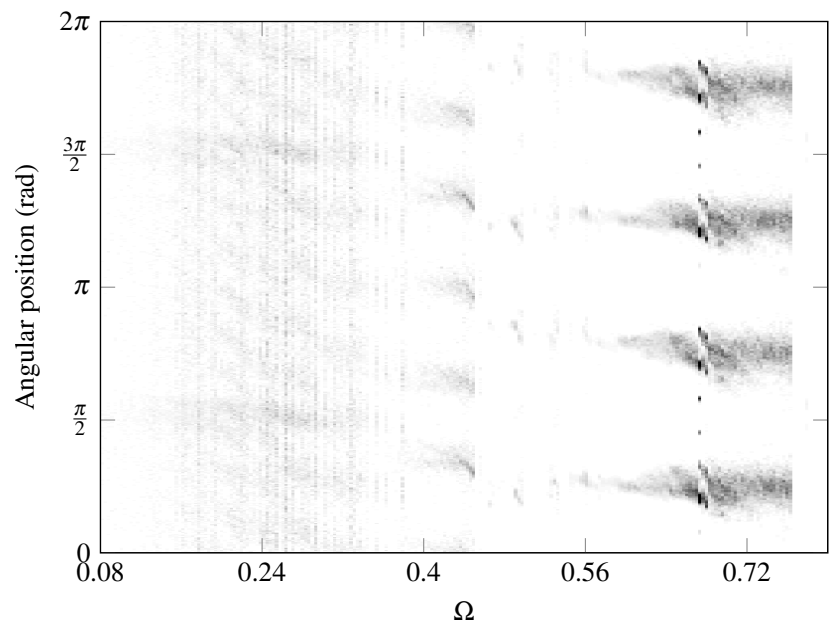

(b) Wear map for adhesive and micro-rupture wear

Figure 5. Wear maps for the comparative study

The model presented in [2] revealed consistency with experimental data: the coating wear pattern and the modal response of the blade is similar to experiments [1]. However, it needs to be calibrated numerically [21] since its wear law is mainly numerical. Our goal here is to show that we can reproduce the same kind of results with the presented model, as a first step toward using phenomenologically based wear mechanisms. Parameter values are determined from our industrial partner data and literature $[8,17]$. Here we only use the adhesive and micro-rupture wear mechanisms. They are believed to be the predominant ones in the original experiment as incursions and temperature were low.

A wide angular velocity range $(\Omega \in[0.08 ; 0.8])$ is considered, and one simulation is carried out for each angular velocity that remains constant over time. The results are analysed through two kinds of graphs:

Wear maps (e.g. Fig. 5) the abradable coating wear profile facing the trailing edge-where most sophisticated patterns are observed-is plotted at the end of each simulation. 


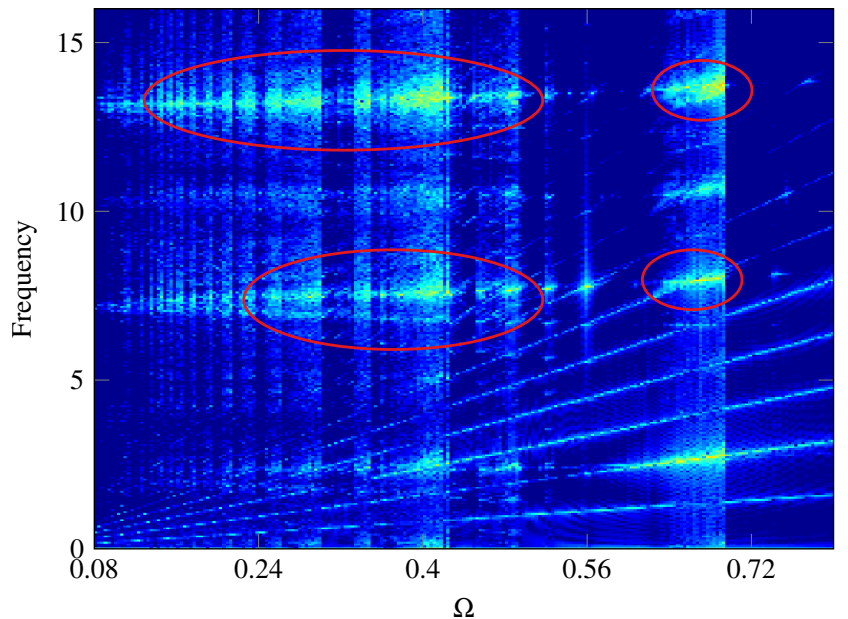

(a) Interaction map for the reference law [21]

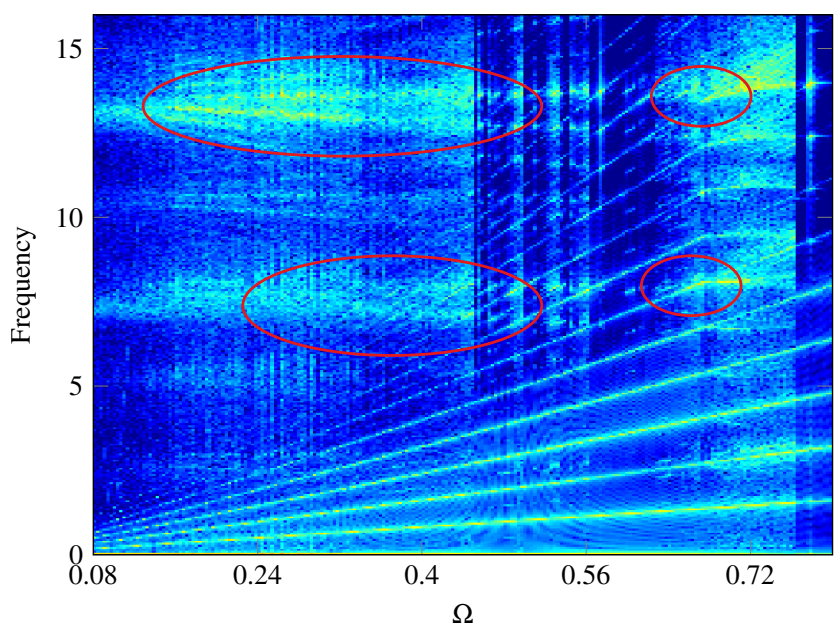

(b) Interaction map for adhesive and micro-rupture wear

Figure 6. Interaction maps for the comparative study

For each angular velocity, meaning for one column of the map, a color code indicates the quantity of abradable removal along the casing circumference: from white where the coating is intact to black where maximum wear is observed [23].

Interaction maps (e.g. Fig. 6) the Fourier transform (spectrum) of the blade edge displacement is plotted for each angular velocity. Low amplitudes are in blue, and frequency peaks in yellow and red.

When looking at the wear maps in Fig. 5, the same kind of patterns can be noticed: strong wear around $\Omega=0.4$ and $\Omega=0.7$, with respectively 6 and 4 wear lobes. Both simulations are in accordance with the actual experiment [1] where 6 lobes were found around $\Omega=0.4$. Note however that the level of wear of the simulation with adhesive and micro-rupture wear laws is much less than with the elasto-plastic wear law. This is because these wear maps are taken after 50 blade turns, where there is no more wear in the case of the elasto-plastic model simulation, whereas it is still going on in the case of the adhesive and micro-rupture simulation.

The interaction maps (see Fig. 6) for the displacement at the edge of the blade also shows similar patterns: the engine order lines represent the contact due to the ovalization of the casing and are the same in both diagrams. Other peaks (inside the red ellipsis of Fig. 6) representing the excited eigenfrequencies of the blade are a match from an interaction map to the other, even if they are more blurry in the case of an adhesive and micro-rupture wear.

\subsection{Preliminary results for a parameter study}

The goal of this study is to compare wear maps for the same structural configuration - blade shape, clearance, casing ovalizationbut with different wear laws.

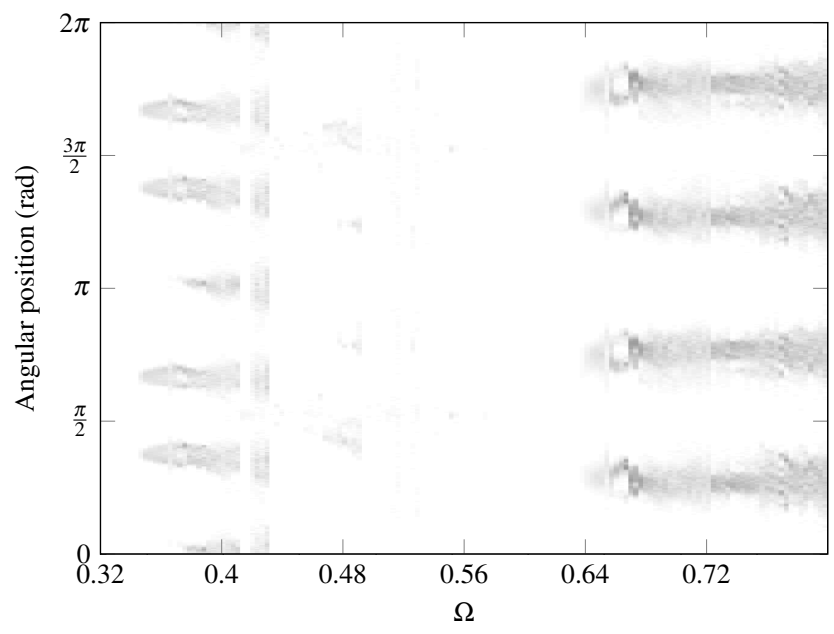

(a) Adhesive wear

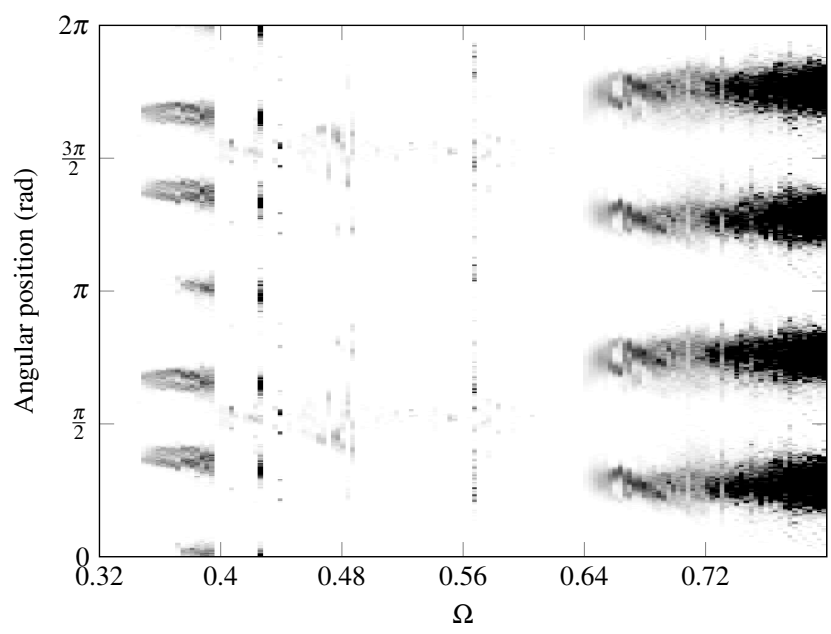

(b) Micro-rupture wear

Figure 7. Wear maps for the parameter study

In Fig. 7, two wear maps are displayed, each one with a different wear mechanism. Except for the level of wear, the patterns are very similar. This seems to indicate that the blade trajectory is mainly governed by the structural configuration of the blade. Note however that the interaction is not finished when the wear maps are extracted, and the wear patterns could diverge significantly from each other had the temporal integration been carried out longer.

\section{Conclusion}

The numerical simulation of blade/casing interaction in the presence of abradable wear is a complex subject. This article derived an approach for modeling wear of the coating, based on the phenomenology of abradable wear mechanisms. Each wear phenomenon is modeled by a simple analytical equation. Then the blade/casing interaction is solved numerically by a 3D explicit numerical scheme. The first results show that an implementation of wear based on these phenomena is capable of reproducing experimental results. A more systematic parameter study is ongoing. It aims at quantifying the influence of each mechanism on the blade dynamics. Also, additional investigations regarding experimental parameters are required in order to calibrate more precisely the proposed wear model parameters: sliding, scratching and toughness tests, analysis of machining chips... 
This model will enable the introduction of thermal effects through a state variable taking into account temperature and which the parameters presented on this study (such as the friction coefficient) may depend on. The model is also expected to reproduce more complex frequency response, as found in experiments [1]. The final objective of this work is to compare the blade response with different kind of abradable materials in order to select the one with minimal induced vibratory response.

\section{Acknowledgments}

Thanks go to Snecma for its technical and financial support.

\section{References}

[1] A. Millecamps. "Interaction aube-carter : contribution de l'usure de l'abradable et de la thermomécanique sur la dynamique d'aube". $\mathrm{PhD}$ thesis. École Centrale de Lille, 2010.

OAI: tel-01200536.

[2] A. Batailly, M. Legrand, A. Millecamps, F. Garcin. "Numerical-experimental comparison in the simulation of rotor/stator interaction through blade-tip/abradable coating contact". Journal of Engineering for Gas Turbines and Power 1342012. DOI: $10.1115 / 1.4006446$. OAI: hal-00746632.

[3] F. Peyraut, J.-L. Seichepine, C. Coddet, M. Hertter. "Finite element modeling of abradable materials - Identification of plastic parameters and issues on minimum hardness against coating's thickness". International Journal for Simulation and Multidisciplinary Design Optimization 2 2008, 209-215. DOI: 10.1051 /ijsmdo: 2008028.

[4] R. Johnston. "The sensitivity of abradable coating residual stresses to varying material properties". Journal of Thermal Spray Technology $182009,1004-1013$. DOI: $10.1007 / \mathrm{s} 11666-009-9378-2$.

[5] M. YI, J. He, B. HuAng, H. ZhOU. "Friction and wear behaviour and abradability of abradable seal coating". Wear 231(1) 1999, 4753 .

DOI: $10.1016 / \mathrm{S} 0043-1648(99) 00093-9$.

[6] X. MA, A. MATthEWs. "Evaluation of abradable seal coating mechanical properties". Wear 267 2009, 1501-1510. DOI: $10.1016 / \mathrm{j}$. wear. 2009.03.044.

[7] M. BOREL, A. NicOll, H. SCHLÄPfER, R. SCHMID. "The wear mechanisms occurring in abradable seals of gas turbines". Surface and Coatings Technology 39-40 1989, 117-126. DOI: $10.1016 / 0257-8972$ (89) 90046-7.

[8] R. K. SCHMID. "New high temperature abradables for gas turbines". $\mathrm{PhD}$ thesis. Swiss federal institute of technology Zurich, 1997. DOI: $10.3929 /$ ethz-a-001809249.

[9] M. Cuny, S. PhilipPon, P. Chevrier, F. GARCin. "Experimental measurement of dynamic forces generated during short-duration contacts: application to blade-casing interactions in aircraft engines". Experimental mechanics 54 2014, 101-114. DOI: $10.1007 / \mathrm{s} 11340-013-9780-z$.

[10] A. Dadouche, M. J. Conlon, W. Dmochowski, B. Liko, J.-P. BEDARD. "Experimental evaluation of abradable seal performance at high temperature". Proceedings of the ASME Turbo Expo. GT2008-51228. Berlin, Germany, 2008.
[11] R. Mandard, J.-F. Witz, X. Boidin, J. Fabis, Y. DesplanQUES, J. MERIAUX. "Interacting force estimation during blade/seal rubs". Tribology international 2014. DOI: $10.1016 / j$.triboint .2014 .01 .026 . OAI: hal-01081384.

[12] C. Padova, J. Barton, M. Dunn, G. Young, M. Adams, M. ADAMS. "Development of an experimental capability to produce controlled blade tip/shroud rubs at engine speed". Journal of Turbomachinery 1272005. DOI: $10.1115 / 1.1934429$.

[13] E. Novinski, J. Harrington, J. Klein. "Modified zirconia abradable seal coating for high temperature gas turbine applications". Metallurgical and Protective Coatings 1982, 255-263.

[14] H. I. Faraoun, J. L. Seichepine, C. Coddet, H. Aourag, J. Zwick, N. Hopkins, D. Sporer, M. HertTer. "Modelling route for abradable coatings". Surface \& Coating technologies 200(22-23) 2006, 6578-6582.

DOI: $10.1016 / j$. surfcoat. 2005.11.105.

[15] R. J. WiLliams. "Simulation of blade casing interaction phenomena in gas turbines resulting from heavy tip rubs using an implicit time marching method". Proceedings of the ASME Turbo Expo. GT2011-45495. Vancouver, Canada, 2011.

[16] T. W. WRIGHT. The physics and mathematics of adiabatic shear bands. Cambridge University Press, 2002.

[17] E. RABINOWICZ. Friction and wear of materials. Wiley-Interscience, 1995.

[18] M. P. GRoOver. Fundamentals of Modern Manufacturing. John Wiley \& Sons, Inc., 2010.

[19] S. BAÏZ. "Etude expérimentale du contact aube/abradable: contribution à la caractérisation mécanique des matériaux abradables et de leur interaction dynamique sur banc rotatif avec une aube". $\mathrm{PhD}$ thesis. École Centrale de Lille, 2011. OAI: tel-00605091.

[20] M. Cuny. "Contribution à la caractérisation locale des couples de matériaux mis en jeu lors du contact rotor/stator dans une turbomachine". PhD thesis. Université de Lorraine, 2012. OAI: tel-00782041.

[21] M. Legrand, A. BAtAilly, C. Pierre. "Numerical investigation of abradable coating removal in aircraft engines through plastic constitutive law". Journal of Computational and Nonlinear Dynamics 7(1) 2011

DOI: $10.1115 / 1.4004951$.

OAI: hal-00627526.

[22] R. CRAIG, C. BAMPTON. "Coupling of substructures for dynamics analyses”. AIAA Journal 6(7) 1968, 1313-1319. DOI: $10.2514 / 3.4741$.

[23] A. Batailly, M. Meingast, M. Legrand. "Unilateral contact induced blade/casing vibratory interactions in impellers: analysis for rigid casings". Journal of Sound and Vibration 337 2015, 244 262.

DOI: $10.1016 / j \cdot j s v \cdot 2014.10 .010$.

OAI: hal-01120157. 